\title{
Mindfulness equity and Western Buddhism: reaching people of low socioeconomic status and people of color
}

\author{
Harrison A Blum ${ }^{1,2}$
}

\author{
Correspondence: \\ harrisonablum@gmail.com \\ ${ }^{1}$ Center for Spirituality, Dialogue, \\ and Service Northeastern University, \\ 360 Huntington Avenue, Boston, \\ MA 02115, USA \\ ${ }^{2}$ Pastoral Care Franciscan Hospital \\ for Children, 30 Warren Street, \\ Brighton, MA 02135, USA
}

\begin{abstract}
This study presents the findings of the first pilot series of the Mindfulness Allies Project (MAP), and focuses on the intersection of mindfulness, Western Buddhism, socioeconomic status (SES), and race. While much has been published about the efficacy of mindfulness meditation with various clinical and non-clinical populations, understudied populations still include people of low SES and people of color. Additionally, while care is often, and appropriately, taken to differentiate mindfulness from Buddhism, the fact remains that Buddhism directly influenced the creation of leading clinical uses of mindfulness, including Mindfulness-Based Stress Reduction and Mindfulness-Based Cognitive Therapy. MAP proposes a model for Western Buddhist centers and teachers, as well as professional mindfulness providers, to offer annual secular mindfulness series in partnership with local organizations serving marginalized populations - those not benefitting from privileged identity factors - particularly in relation to race and class. MAP is founded on a vision of mindfulness equity-or equal access to mindfulness teachings. This MAP pilot series consisted of five weekly mindfulness classes. Classes were provided free of charge at a community center serving low-income residents, with childcare during and dinners after classes also provided free of charge. Participants largely consisted of people of color earning less than $\$ 15,000$ per year. Quantitative and qualitative surveys administered at the conclusion of the final class revealed highly positive feedback, and suggest that the MAP model could benefit both marginalized communities as well as Buddhist centers' and teachers' desire to diversify those benefitting from their teachings in the West.
\end{abstract}

Keywords: Mindfulness; Buddhism; Western Buddhism; Meditation; Socioeconomic status; Race

\section{Background}

One good definition of mindfulness is "awareness of present experience with acceptance" (Germer 2005). Rather than being concerned with ushering in any certain state, mindfulness brings an accepting curiosity to what is already here and now. Buddhist practices of meditation are one long-standing source for cultivating mindfulness, and are a significant influence on the present intersection of mindfulness and Western psychology. Bhikkhu Analayo, a German-born Buddhist monk and scholar, writes that the word mindfulness is a translation of the Pali word sati, which he also translates as "awareness" (Analayo 2003). According to the Satipatthana Sutta, one of the most 
important Buddhist teaching on mindfulness, "the meditator is never instructed to interfere actively with what happens in the mind...That is, sati does not change experience, it deepens it" (Analayo 2003).

The concept of sati, as explained by Analayo, has directly informed the development of clinical mindfulness-based interventions over the past thirty years. MindfulnessBased Stress Reduction (MBSR), developed by Dr. Jon Kabat-Zinn at the University of Massachusetts Medical School in 1979, was the first of this wave, and can be seen as something of a mother figure to the related interventions that followed. In the 1990s, influenced by MBSR, doctors Zindel Segal, Mark Williams, and John Teasdale developed Mindfulness-Based Cognitive Therapy (MBCT). Both Kabat-Zinn and Teasdale have directly credited Buddhist teachings, specifically those from the Insight Meditation tradition of Western Buddhism, as being a dominant influence on the creation of their methods (Gilpin 2008). Such crediting is significant as MBSR and MBCT are among the most studied forms of clinical mindfulness through which benefit to practitioners has been demonstrated. As the efficacy of clinical mindfulness has played a large role in the popularization of mindfulness at large, a connection can be directly made between the teachings of Insight Meditation and the expansion of mindfulness in popular culture. As such, the Insight Meditation tradition has an opportunity, if not a responsibility, to engage actively in how and to whom mindfulness is taught outside of its centers.

Insight Meditation is one of the primary Western founded modern traditions of Buddhism. The Insight Meditation community was birthed in the 1960s by a handful of Westerners bringing back their skills and experiences from intense Theravada Buddhist practice in South and Southeast Asia. Three of these individuals, Sharon Salzberg, Jack Kornfield, and Joseph Goldstein, co-founded the Insight Meditation Society (IMS) in Barre, Massachusetts, in 1975 as a residential retreat center. In the late 1980s Kornfield helped found the Spirit Rock Meditation Center in Marin County, California. In 2010, IMS hosted just fewer than 3,000 retreatants (Insight Meditation Society 2011a, b) ${ }^{\text {a }}$. According to Spirit Rock Finance Manager Mark Sponseller, Spirit Rock hosted almost 3,500 retreatants in 2010, which grew to approach 3,800 in 2011. While estimating the total number of Insight Meditation community practitioners is difficult, retreats of this type are offered in at least 24 U.S. states, with non-residential practice centers and meditation groups existing in much higher numbers across the country (Insight Meditation Society 2011a).

While clinical mindfulness has been informed by the Buddhist tradition of Insight Meditation, it would be misguided to say mindfulness is Buddhist. Kabat-Zinn states "there is nothing particularly Buddhist about it...It is an inherent human capacity" (Kabat-Zinn 2003). It is the deliberate fostering and sustaining of this capacity that Buddhist meditation, and several current therapy models, attempt. While some people have propensities for mindfulness without formal training, mindfulness training has been shown to correlate with increased continuity of mindfulness (Brown and Ryan 2003). "Mindfulness per se is not unusual; continuity of mindfulness is rare indeed" (Germer 2005).

While clinical applications of mindfulness have grown over recent decades, a parallel, though smaller, growth has occurred within the Insight Meditation community in practice groups for people of color (POC). Many regional Insight centers now offer POC sitting groups and the two main Insight retreat centers, Insight Meditation Society (IMS) and 
Spirit Rock, offer annual POC retreats. Teacher training within the Insight community has also shifted toward greater diversity of teachers and served communities. Spirit Rock's fourth Community Dharma Leader (CDL) training began in 2010 with an accepted class consisting of $38 \%$ people of color, compared to an average of $6 \%$ people of color within the three previous CDL iterations and the three previous Dedicated Practitioner Programs (a similar two-year training) (Yang 2012). Other examples of intentional engagement with race include the Cambridge Insight Meditation Center's (CIMC) six-year "Diversity and Inclusion" review, concluded in 2009, and the Insight Meditation Society's three-year action plan on racial diversity, begun in 2013 (CIMC 2010, IMS 2014).

A window into the motivation for such efforts toward inclusion can be found on the IMS website's page on "Commitment to Diversity", wherein they state "We are clear that, if people of color feel IMS is just like many other predominantly white institutions in the country, then it cannot be a true spiritual refuge. In that case, we would be failing in our mission" (IMS 2014). The first of five goals IMS lists for this action plan is "To deepen the understanding and undoing of internalized and institutional racism in order that leaders and members throughout IMS's community can act with wisdom and compassion, informed by sensitivity to racial and cultural realities" (IMS 2014).

While class is being addressed less than race, some Insight centers offer need-based scholarships for classes or retreats. As worthy and essential as these efforts toward inclusivity are, their focus is limited to inviting in rather than going out. The MAP model (see Additional file 1) complements efforts to be inclusive with a move to meet marginalized people where they are, through the channels already reaching them.

Such measures to increase access to Buddhist teachings across race and class are perhaps more timely now than ever. The World Hunger Education Service (WHES) reports that almost half the U.S. population is poor or low-income (WHES 2011a, b). In 2010, 17.2 million U.S. households, 14.5\%, were food insecure, "the highest number ever recorded," while families with children living in poverty or deep poverty have increased over the past ten years, with an upward spike since 2007 (WHES 2011a, b). The WHES cites the three main causes of poverty in the United States as "poverty in the world; the operation of the political and economic system in the United States which has tended to keep people from poor families poor; and actual physical, mental, and behavioral issues among some people who are poor" (WHES 2011a, b). It is this third potential cause of poverty that MAP seeks to ameliorate and redress by offering mindfulness training.

A disproportionate number of people of color live in poverty in the United States due to systemic structural racism. On the individual level, this operates as prejudice. A study on job applications found that "those with white-sounding names received 50 percent more invitations for an initial interview than applicants with black-sounding names" (U Chicago/MIT in Lui et al 2006). Prejudice becomes structural racism at the institutional level. While beyond the scope of this paper, much has been written on the culpability of United States' laws and policies in this regard throughout history as well as today (Alexander 2010, Lui et al 2006).

The 2010 U.S. Census Supplemental Poverty Measure estimates 16\% of the total population is living in poverty, which amounts to one individual earning just over $\$ 11,000$ a year. Eleven percent of whites, $28 \%$ of Hispanics, $25 \%$ of Blacks, and $17 \%$ of Asians live in poverty in the U.S. (US Census 2010). Twenty eight percent of those 
living in poverty in the United States are children (WHES 2011a, b). More women than men live in poverty, a statistic exacerbated by women more often bearing the multiple burdens of child raising (U.S. Census 2011, "Poverty of People, by Sex: 1966-2010"). Living in poverty greatly increases the likelihood of incarceration (Moskos 2011), as does being a person of color (Children's Defense Fund 2007). Similar to the causes of poverty mentioned above, governmental policies and structural racism are contributors to the disproportionate incarceration of poor and non-white people in the United States (Reiman 2009). About 2.3 million people are incarcerated in the U.S., more than $1 \%$ of the adult population (Moskos 2011). The U.S. incarceration rate has increased by $500 \%$ since the 1970s, and now stands at five times the word's average.

The American Psychological Association (APA) (2007) states, "Socioeconomic factors and social class are fundamental determinants of human functioning across the life span, including development, well-being, and physical and mental health". Living with low SES can elevate levels of both acute and chronic stress, resulting in higher rates of "hopelessness, hostility, anger, and depression" (APA 2007). These challenging emotions in turn have medical ramifications, including increased rates of cardiovascular disease and mortality (APA 2007). "Depending on the criteria used, some $60-90 \%$ of all physician visits are for stress-related disorders" (Siegel 2010). While not every person living with low SES suffers health issues related to their SES, it is important to note the reality that SES and health can be interrelated.

MAP offers a model to wed the good intentions of Insight Meditation centers and teachers with the acute needs of some people living with low SES. Other Western Buddhist traditions that include expertise and teachings on mindfulness could also be good candidates for the model. While being of low SES is certainly distinct from being a person of color, the unfortunate truth remains that people of color suffer in higher percentages from a life of low SES. MAP's directing mindfulness training toward people of low SES is thus also an approach that stands to reach large numbers of people of color, depending on the specific region. A handful of studies have already shown mindfulness-based interventions to be effective with low-income populations (Dutton et al. 2011; Roth and Calle-Mesa 2006; Roth and Robbins 2004).

More broadly, the MAP model could be implemented by professional mindfulness providers working outside of Buddhism. Unique from organizations already teaching mindfulness with low-income communities, such as the Holistic Life Foundation and the Lineage Project, MAP is based on annual four to six week mindfulness series-a level of commitment small enough for mindfulness teachers to volunteer and large enough for participants to benefit.

While MAP does focus on increasing mindfulness equity particularly in regard to race and class, the model is also applicable to other marginalized populations, or those not benefiting from privileged identity factors. Under this view, one could say women are marginalized to the benefit of men, people of color are marginalized to the benefit of white people, and the poorer are marginalized to the benefit of the wealthier. Other marginalized groups include people with physical or mental disabilities, those not identifying as heterosexual, and those seen as old. A person might be assigned to one or more marginalized categories as perceived by normative cultural views.

It is important to note that such categories of marginalization are often overlapping. Barbara Risman, head of the Department of Sociology at The University of Illinois 
Chicago, states, "There is now considerable consensus growing that one must always take into consideration multiple axes of oppression; to do otherwise presumes the whiteness of women, the maleness of people of color, and the heterosexuality of everyone" (APA 2007). The name Mindfulness Allies Project thus points to the multiple identity factors of both MAP teachers and MAP participants. While certain MAP teachers may share marginalized identities with class participants, it is unlikely that a MAP teacher will share every marginalized identity facet with every class participant, thus making MAP teachers allies to some in the class.

Amidst MAP's promise, there are certainly risks. While statistics are hard to come by, a high percentage of Western Buddhists and professional mindfulness providers are likely white, well-educated, and of middle or upper class. In a 2005 study of over 800 people "with considerable experience with mindfulness meditation", 76\% had received a graduate degree or completed some graduate school (Jacob et al. 2009). The group's reported median household income was between $\$ 70,000-80,000$ per year, while the national median for that year was $\$ 46,326$ (Jacob et al. 2009).

MAP teachers, especially white ones, need to racialize their own whiteness and avoid slipping into the "white savior" mindset, in which those with privileged identities (white, mid-high SES) think they know what those with target identities (people of color, low SES) need and deliver it in a one-way, temporary exchange. Conversely, the MAP model counsels connecting with partner organizations before teaching classes, both to form real relationships and to assist the classes in being population-specific. MAP teachers are advised to share leadership roles with members of partnering organizations, and to have training beyond mindfulness in practices and competencies that support their sensitivity and efficacy, such as anti-racism training, class awareness, feminism, non-violent communication, and Insight Dialogue. Attention is guided toward mutual respect and the sustainability of interventions over time.

What follows are the findings from the first pilot series of the Mindfulness Allies Project, conducted in the spring of 2012.

\section{Methods}

\section{Setting}

This study shares the findings of a five-part mindfulness class series held at a community center in a major city in the northeastern U.S. The community center focuses on providing services to low-income residents of the city, and its programs include after school and summer youth programs, a food pantry, at-risk young adult support, parent training and support, computer skills training, men of color health care advocacy, and neighborhood community building initiatives. Of the more than ten official neighborhoods of this city, the community center is located in the neighborhood with the highest percentage of affordable housing, a percentage over twice the city-wide average (Community Development Report 2010). The neighborhood also has a higher than average youth population and a lower than average adult population with bachelor, graduate, or professional degrees (Community Report 2010). The average percentage of non-white residents in the city is $32 \%$, while in the center's neighborhood it is $54 \%$ (Community Report 2010).

The MAP teacher for this pilot series was a white male, trained within the Insight Meditation tradition, as well as at the graduate level in Buddhist ministry. He had 
professional experience teaching mindfulness in hospital, university, and workshop settings. He had anti-racism and anti-oppression training with VISIONS Inc. and had taken graduate level courses on race, class, incarceration, and feminism. Previously, he had lived within a few blocks of the community center and had volunteered briefly during one of their summer youth programs.

The class series was promoted by the community center as well as by other local service agencies working with at-risk populations.

\section{Sample}

The number of participants in attendance for each of the five classes was as follows: 6 , $10,4,8$, 9. Women outnumbered men, with the average percentage of female participants per class at $88 \%$. On average, classes were comprised of $45 \%$ white people and $55 \%$ people of color, with an average breakdown of 31\% African Americans and 24\% Latinas. No single class had less than $50 \%$ people of color. Eight people attended at least three of the five classes, with four of them attending four classes and one person attending all five classes.

Demographic information was collected at the conclusion of the last class from participants who attended at least three classes. Of this group of eight people, seven answered questions on race, age, and income. Regarding race, 3 were white, 2 black, and 2 Latina. Regarding age, 1 was in their thirties, 3 were in their forties, and 3 were in their fifties. Regarding income, 5 participants earned less than $\$ 15,000$ per year, 1 earned between $\$ 15,000-\$ 30,000$, and 1 earned between $\$ 30,000-\$ 45,000$.

\section{Measures}

An optional questionnaire was administered at the conclusion of the last class to participants who attended at least three classes. All eight participants who had attended at least three classes chose to complete the questionnaire. The questionnaire consisted of seven Likert items followed by fifteen short answer questions (Additional file 2). Questionnaires were submitted anonymously and the MAP teacher left the room while participants filled them out. Participants were told their responses would be included in a graduate school thesis as well as possible future publications. Each person completing a questionnaire was given a $\$ 10$ gift card to Target as a gesture of appreciation for their taking extra time to complete the form.

\section{Procedure}

The main objective of the mindfulness series was to train participants in mindfulness techniques to ameliorate the challenges of inner (mental, emotional, physical) and outer (environmental, structural) struggles they face. Inner struggles addressed in the classes included stress, anger, self-judgment, and chronic pain. Outer struggles addressed included racism, financial hardship, limited mobility, and family obligations. While such inner and outer challenges inform each other, they were framed as distinct topics to facilitate conversation.

Anchors for mindfulness practice included the breath, body sensations, walking, eating, and brief hip-hop dance exercises. Each session of mindfulness practice ended with an offering of kindness toward one's self. Themes for the five classes were Introduction 
to Mindfulness, Mindfulness of the Body, Mindfulness and Stress, Mindfulness and Oppression, and Integrating Mindfulness into Daily Life. The first class began by hearing from participants on why they chose to attend and what they wished to get out of the series. The final class included some discussion of ethics and integrity being informed by one's self-understanding.

Classes were each one hour long and each progressed through the following format: check-ins, brief guided practice, mindfulness instruction, longer guided practice, group debrief on practice, brief loving-kindness practice. Free childcare was offered during each class, supervised by an adult in a nearby room. Free dinners were offered at the close of each class.

Three one-page handouts were distributed over the course-a guide to home practice, suggestions for meeting oppression with mindfulness, and information on local mindfulness resources-after the first, third, and fifth class respectively. The handout on meeting oppression with mindfulness was a slightly adapted version of the "Nine Instructions to Overcome Oppression", as used by the Radical Mindfulness Training (Hick and Furlotte 2010). The local resources handout listed information on weekly beginner classes and a monthly people of color group at a local Insight Meditation center, which was just a half mile away, as well as information on a nearby Christian Centering Prayer group and a local Mindfulness-Based Stress Reduction teacher.

\section{Results}

Seven Likert items and fifteen short answer questions were administered at the close of the last class to participants who had attended at least three of the five classes. Results were largely positive and self-reported outcomes included increased self-awareness, self-acceptance, self-love, and self-forgiveness, decreased stress, improved relationships, improved attendance to doctor visits, improved relationship to chronic pain, heightened sense of being alive, and changed/improved relationship with God. In the words of one participant, "I feel like a weight has been lifted off my shoulder".

The responses to the Likert items are presented in Figures 1, 2, 3, 4, 5, 6 and 7. Of note is that all eight surveyed participants responded with true or very true to a question asking whether the class series was helpful. Additionally, seven participants responded to a statement about whether the series made them want to practice mindfulness more in the future and all responded that was "very true".

In response to the short answer questions, four of the eight responding participants answered a question about what might be changed to make the classes better with suggestions to make the classes longer and to have more sessions. One participant answered this question with the suggestion to offer more introduction and support for people to address oppression and other challenging life issues. Some questions about noticing certain life changes since beginning the classes were answered to the effect of "no change". Otherwise, the feedback was predominantly positive and is reported below, preceded by the respective questions. Not every participant answered every short answer question.

1) What made you interested in attending these classes? Why did you first show up?

- "To try to have some control over my very stressful life. Also to make changes/ adjustments in the way I respond when under a lot of stress". 


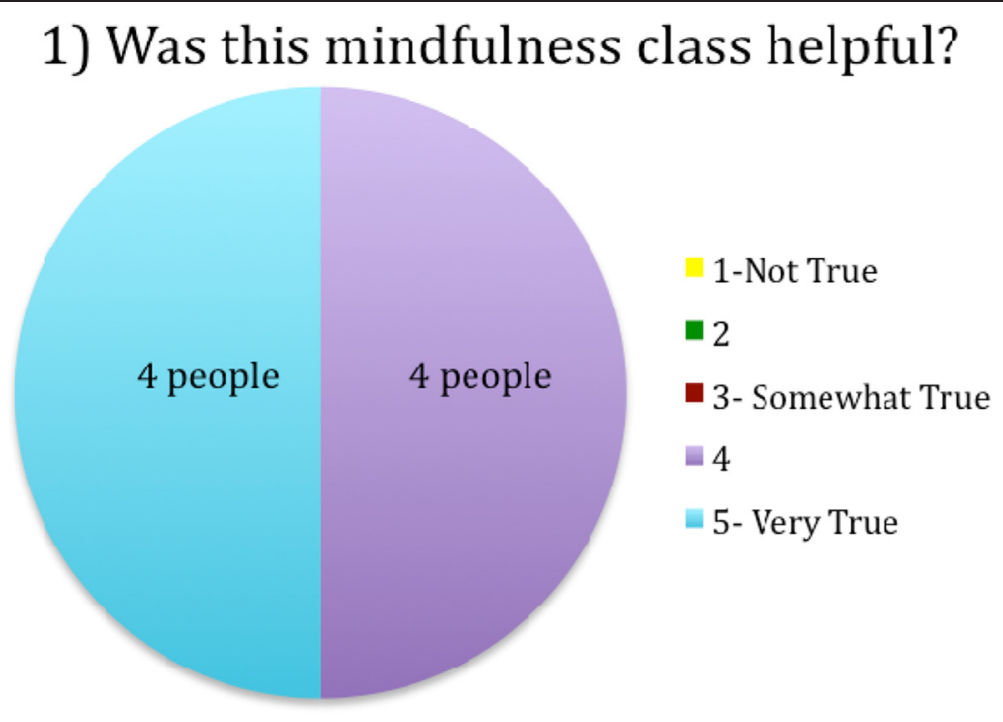

Figure 1 Likert question on whether the class was helpful.

- "stress, disappointments, lost patience".

- "Wanted to continue to explore mindfulness meditation. Thought the class would also support some life transitions I'm currently going through".

- "I am stressed in my daily life and I had already thought about doing some form of meditation but had not made the time. This course was convenient because it was close by in my neighborhood and it offered day care which is something very important for me, on top of that there was going to be dinner served and that was the icing on the cake".

- "Saw the sign-and have been interested in mindfulness in the past. Since I saw the sign @ the Food Pantry and 'dinner will be served' was printed on the sign I showed up".

2) Have you noticed any changes in how you manage stress or other life demands since these classes started? Please describe any changes if so.

- "I believe I learned to be more aware of different situations and have more acceptance and to be less judgmental. I learned that pain is inevitable. I knew it but I accepted it more as a part of life not as a punishment".

- "Bring focus to my breath + self more frequently. This is good, since that is what it is all about. More conscious of saying what is on my mind clearly when I speak to someone".

- "It made me more aware of my surroundings. How to slow down and deal with my demands on a singular/one at a time and not overload myself".

- "Yes, I seen a lot of changes. Since the first class I learned how to deal with certain stressful situations. Now when I see myself getting stress I stop, pause and clear my head".

3) Have you noticed any changes in your social life with friends or family since beginning these classes? Please describe if so.

- "Yes, I don't get mad or irritated that easily with people I used to get mad at. I feel like a weight has been lifted off my shoulders; relationships are so much better". 


\section{2) Did you enjoy this mindfulness course?}

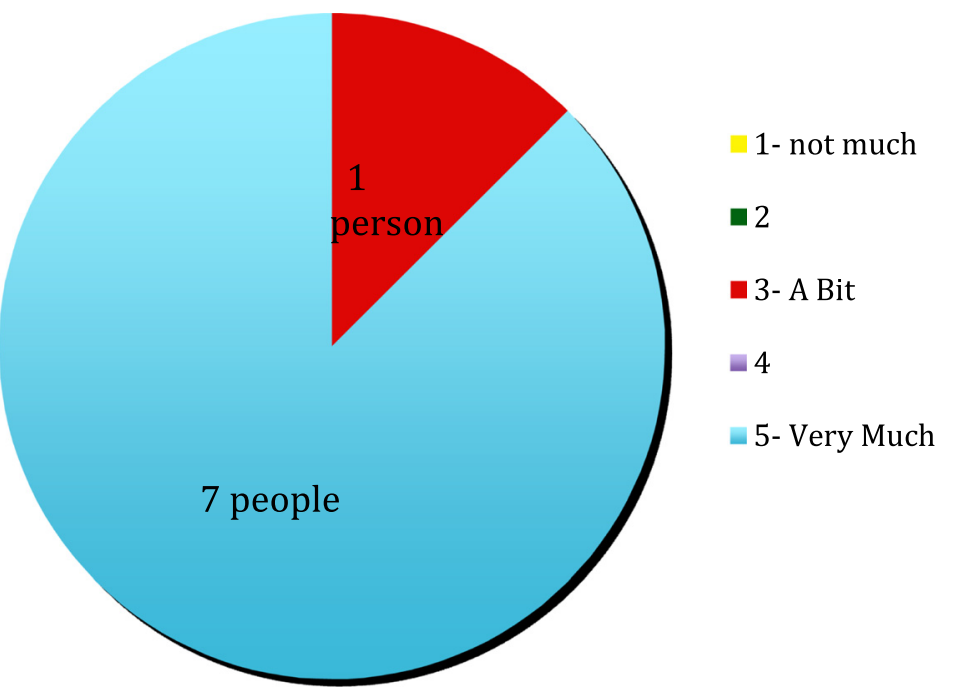

Figure 2 Likert question on whether participants enjoyed the course.

- "I am being more accepting of my friends as they are rather than telling them how to change".

- "I went to all my [doctor] appointments and did not cancel any".

- "Clearer communication @ least w/ one new intelligent friend in particular".

4) Have you noticed any changes in how you feel about yourself since beginning these classes? Please describe if so.

- "Yes, more accepting of some negative feelings about self-hope to move on towards more positive regard!"

\section{3) Were the pace and the instructions of classes appropriate?}

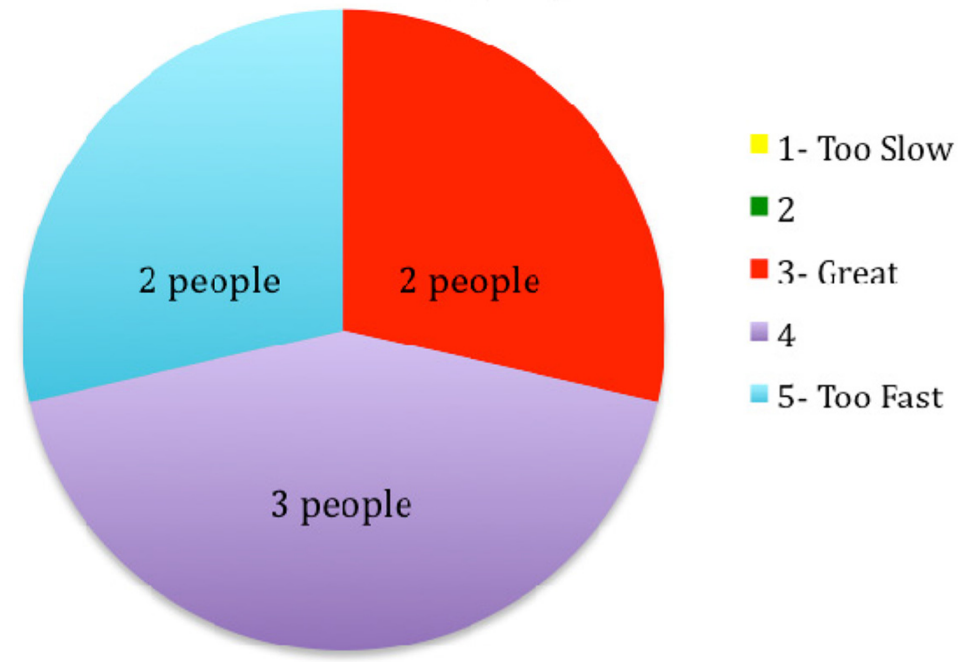

Figure 3 Likert question on the pace and instructions of classes. 


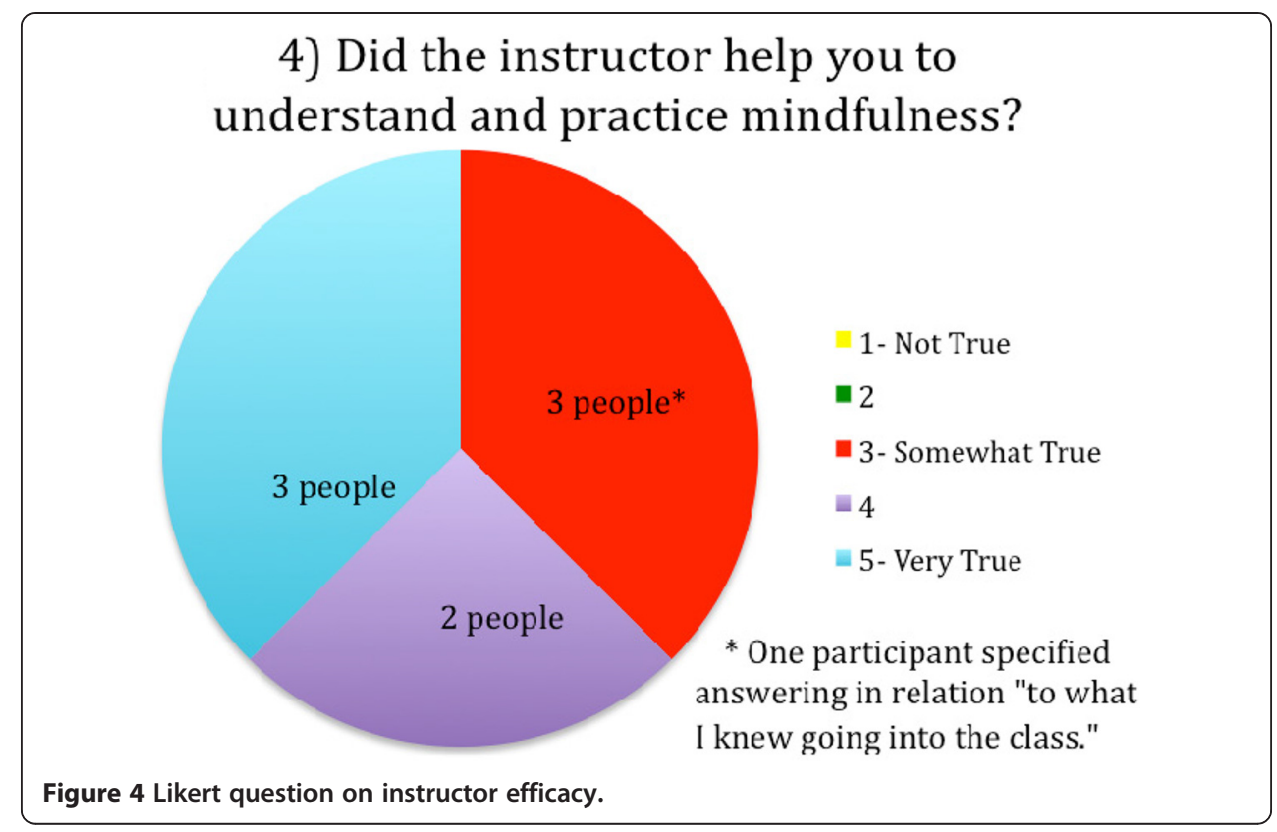

- "I was very proud of my self when I shared with others that I had been able to leave my home to do this class and be with people".

- "I feel at ease with myself, don't feel stressed as much and I feel better with the new person I am becoming".

- "This class has made me more aware of how important it is to have time to de-stress, think about the way I feel before responding to a situation".

- "I am more forgiving of myself and the mistakes I make. I think I used to see natural consequences of my actions as punishment for being 'bad' so I deserved it".

6) Since these classes began, has mindfulness practice affected your physical health in any way? If so, how?

- "I started to control and understand my chronic pain".

- "A little bit. I feel a lot more alive and willing to do more things to make sure I am not stressed".

7) Since these classes began, has mindfulness practice affected your mental well-being in any way? If so, how?

- "This training has allowed me to be aware of self".

- "Increased self-awareness, increased integrity always improve mental well-being. So does food that is nourishing".

- "Yes, my mind is a lot more clear. I can think before acting".

8) Since these classes began, has mindfulness practice affected your spiritual life in any way? If so, how?

- "I am someone who used to be religious and felt disappointed and rejecting of God. Now I'm starting to wonder if my concept of God was wrong and if blaming God for certain events might be off the wall. Perhaps God is not the traditional omnipotent cause of events as reward or punishment as $\mathrm{He} / \mathrm{She}$ is often described".

- "I started to look on events with different angles". 


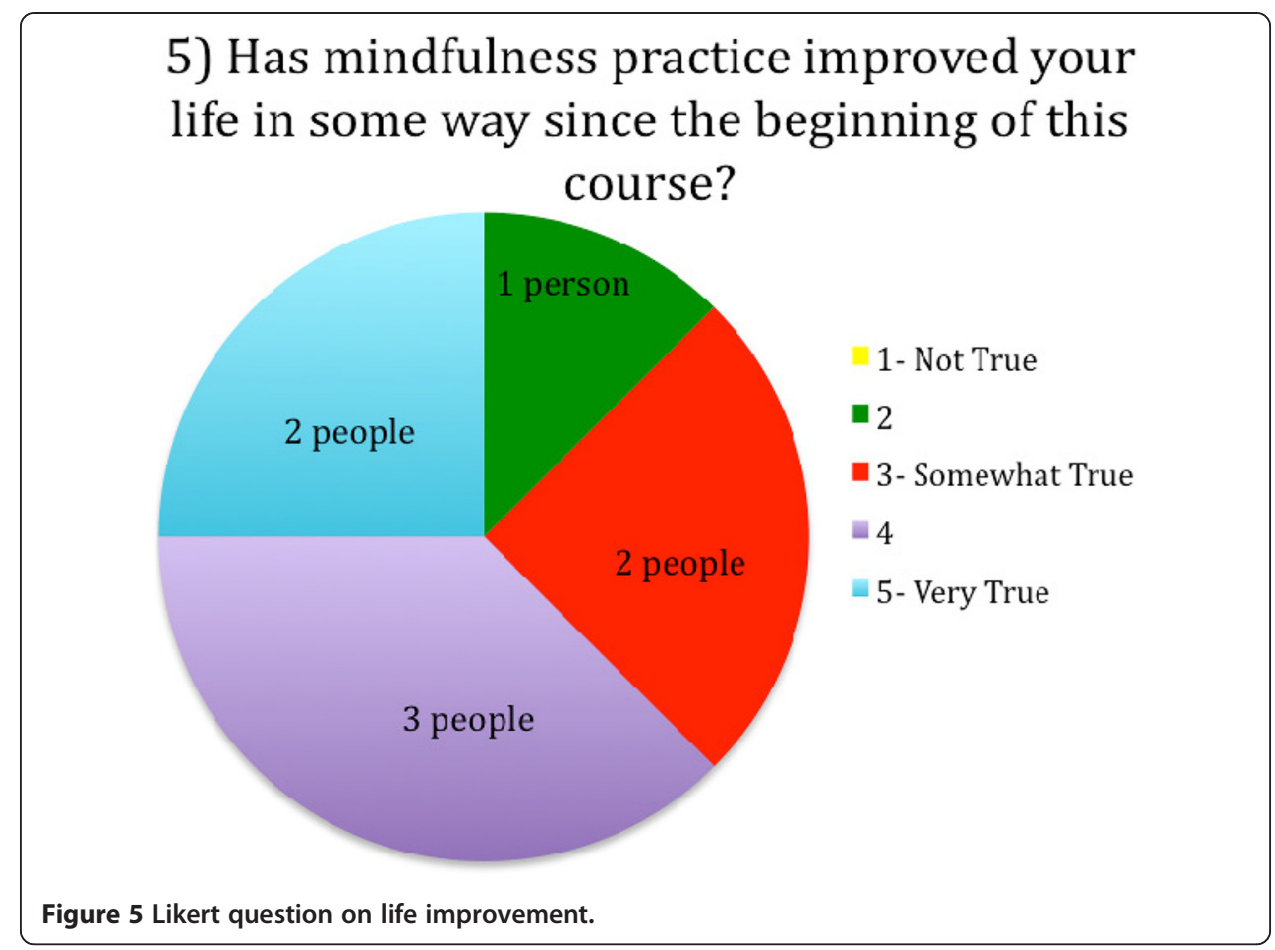

9) Since these classes began, has mindfulness practice affected experiences of oppression or worldly problems you might face in any way? If so, how?

- "It is very hard to put it into practice when you're going through the event; However, it has allowed me to look back and view different way in how to handle the situation the next time around".

- "Yes, made me more painfully aware".

- "Not yet. I hope it does".

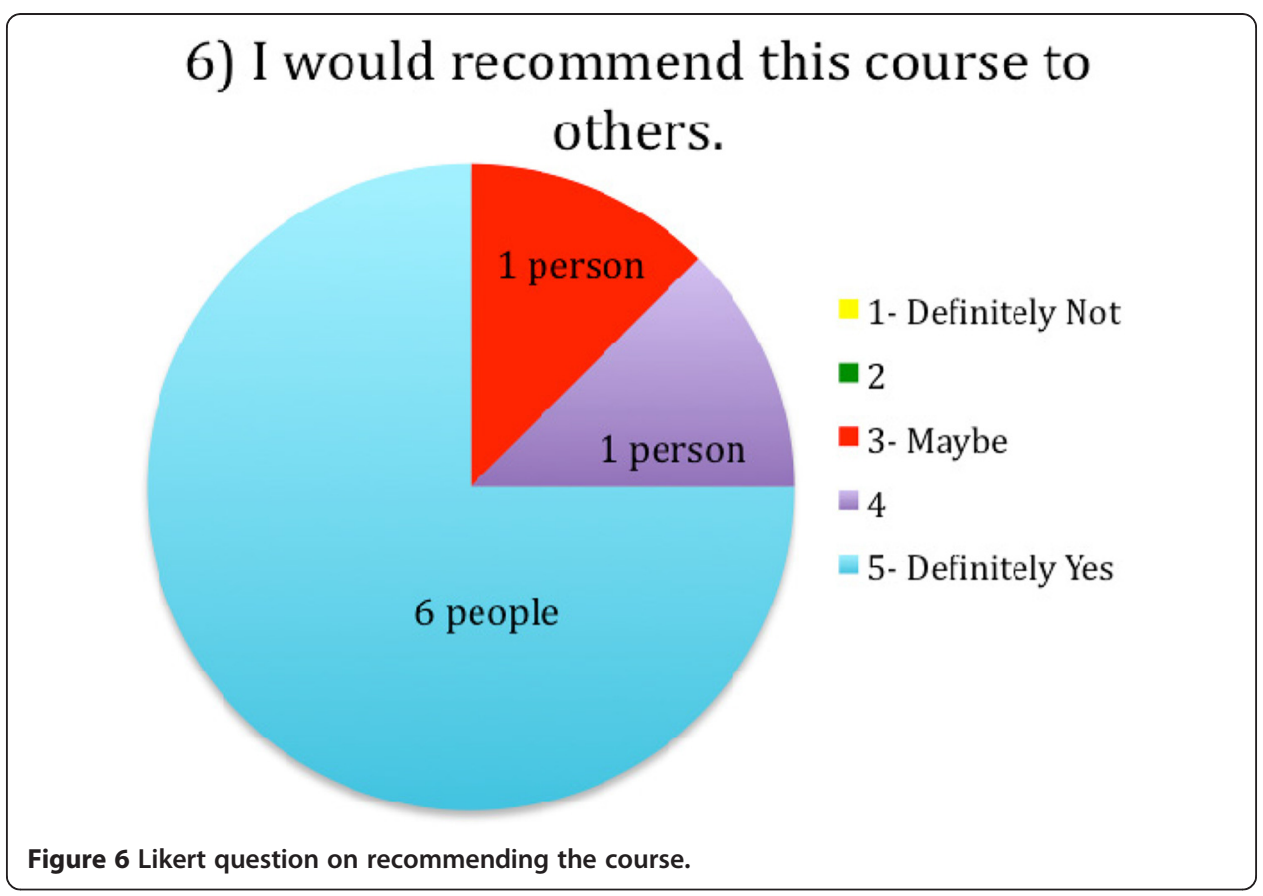




\section{7) Taking this course has made me want to practice mindfulness more in the future.}

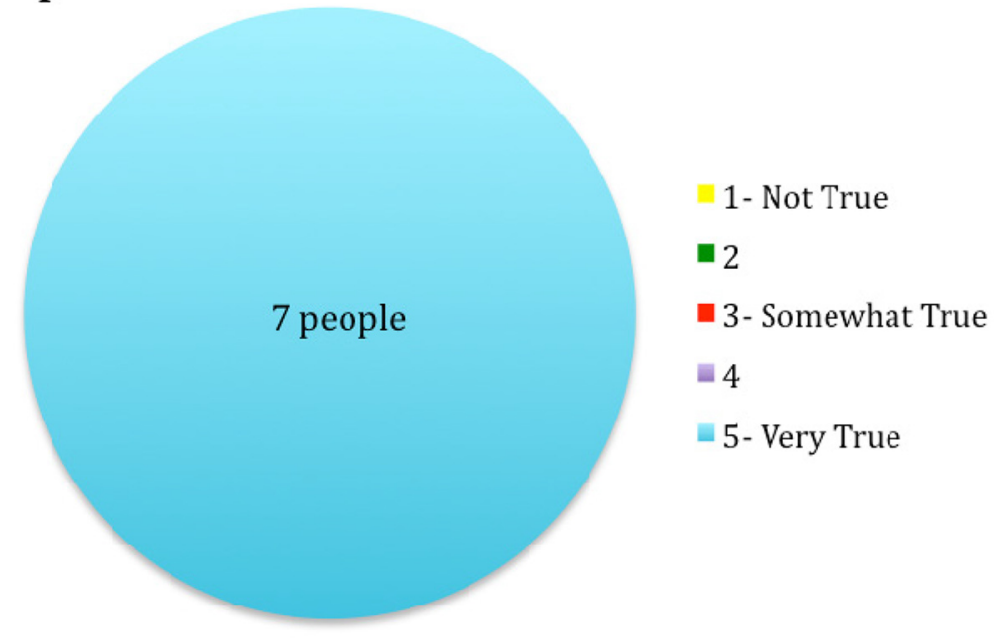

Figure 7 Likert question on future mindfulness practice.

10) Since these classes began, have you practiced mindfulness outside of class time at all? If you did, what was it like to practice? What happened?

- "It feels like I have this great secret that I share between my mind, heart \& soul, and it makes me smile and feel love for myself, something that is very very hard for me".

- "Yes, and it was helpful-primarily while meditating, but at other random times as well. When mindfulness came back to me @ random times it was a pleasant experience".

- "Yes, the opportunity \& location have increased. My ability to practice in diverse environments has increased".

12) What stood out for you from these classes?

- "The gentle soul of the teacher, his ability to convey information to me as if he know me for years. Although I have taken similar classes before it wasn't until now...that I grasped the mindfulness meaning. For me is the first step to beginning to love myself, something I have been trying for over 50 yrs".

- "The use of movement in the meditation done in very creative ways".

- "I liked the diversity of the participants".

- "That practicing mindfulness is more simple than I thought it to be".

- "The different ways they have for mindfulness training and the different ways people can use it".

\section{Discussion}

As demonstrated by these findings, a short-term community based mindfulness series can be an effective way of introducing people to the practice who might otherwise not have chosen or been able to pursue mindfulness instruction. As mentioned in the written feedback, as well as in person, providing the classes, childcare, and dinners free of charge was a significant enticement and was for some what allowed them to attend. One 
participant made the comment that she had wanted to try meditation for years but was not able to for lack of money and available childcare.

Feasibility on the side of the MAP mindfulness teacher is also an important consideration. For the MAP model to succeed, it must be sustainable for teachers as well as attractive to participants. For this pilot series the MAP teacher worked for about 7 hours each of the 5 weeks of class, divided between food shopping, cooking, class planning, class teaching, check-in emails and phone calls to participants, and handout printing. While check-in emails and phone calls to participants between classes are not specified in the MAP model, these were seen as good practices to encourage class attendance and offer support between meetings. The teacher also spent about 10 hours prior to the series communicating with representatives of the community center, promoting the series, and writing the questionnaire. Part of this time included his attending a holiday party at the community center which allowed initial relationships to be formed between the MAP teacher and several community center staff members. Given these approximations, the total amount of time devoted to creating and running this pilot series was about 45 hours.

In terms of finances, the series cost about $\$ 350$ to produce. About half of these funds were used to provide childcare during and dinner after each class free of charge. Childcare was utilized during four of the five classes, with the number of children present ranging from one to three. The teacher home-cooked and brought dinners for each class, and most participants stayed to eat together. The average cost per person per meal was around $\$ 2$, as compared to a quoted cost of $\$ 7$ per person for catered platters. These dinners greatly aided the group getting to know and trust each other. The children rejoined the group to eat with the adults, and conversation ranged from mindfulness practice to daily life to favorite recipes.

The other half of the funds were used to provide \$10 Target gift cards for completing the feedback questionnaire and to send each participant a copy of The Power of Now as a concluding gesture. Funding for this pilot series was drawn from dana (donations) from four previous Buddhist workshops the MAP teacher had offered, two of them at regional Insight Meditation centers.

While 45 hours and $\$ 350$ are not small contributions, they do seem reasonable to consider offering for a Buddhist center or mindfulness provider to be of service to local marginalized community members. If team-taught, the responsibilities could be delegated and the hours divided. Whether Buddhist centers choose to embark upon such a project remains to be seen. Letters of introduction and invitation to participate in MAP, along with a hard copy of the MAP founding paper and a summary of this pilot series, were mailed to IMS and Spirit Rock as well as to six of the largest local Insight centers in the U.S. with only two centers responding and none of them choosing to offer a MAP program themselves.

Among the local centers contacted was the location within a half mile of the community center that housed this pilot series. In addition to the above mentioned materials, a formal one-page proposal was asked for and presented to this center, seeking formal membership for a $2^{\text {nd }}$ MAP series to be run at the same community center in the summer of 2013. Included in the proposal was the request to endorse the MAP teacher as affiliated with the center, and to provide $\$ 400$ to fund a six week series. The proposal was declined, with one sentence of explanation in an email: "At this time, the center is 
involved in a year-long endowment campaign and the center cannot commit to anything extra" (personal communication 2013). To be fair, this Insight Meditation center only covers $66 \%$ of its operating costs with program and membership fees, with the remaining $34 \%$ needed to be raised by special fundraisers and an annual appeal (Executive Director letter 2014). On the other hand, given that their annual appeal fundraising goal is over $\$ 100,000$, it does lead one to wonder if they cannot spare $\$ 400$ toward establishing positive neighborly relations in their community.

Despite this proposal being declined, a second MAP series was run in the summer of 2013, taught by the same MAP teacher in partnership with the same local community center. Participation and outcomes for this second pilot series were similar to the previous iteration, and the series was again funded out of pocket by the MAP teacher. Translation into Spanish was also made available by an interpreter during this second pilot series. There was no MAP series offered in 2014, as efforts were instead focused on networking to spread awareness of the model and to recruit collaborators.

While beyond the focus of this paper, it is worth sharing that as a result of the second pilot series the MAP teacher was invited by a staff member of the hosting community center to teach a one-hour mindfulness workshop to the lay ministers of her evangelical Christian church. These lay ministers visit and offer pastoral care to congregation members. The mindfulness workshop was designed and offered to support them in this work. At the conclusion of the workshop, anonymous Likert item surveys were administered, again with largely positive feedback. All seven participants answered that it was "somewhat true" to "very true" when asked if the class was helpful and whether they thought mindfulness practice could help them in their lay ministry. Additionally, six of the seven participants answered that it was "true" to "very true" when asked if they would like to practice mindfulness more in the future.

In addition to imparting skills in mindfulness training, the MAP teacher gained further facility in connecting across religious difference, and the workshop included a discussion of mindfulness practice as learning to love one's self the way Jesus loves us. The fact that the MAP teacher was invited to teach this workshop demonstrates a recognition of value and an initiative for programming beyond the part of the MAP teacher. This is precisely the type of interfaith, intercommunity connection, collaboration, and mutual benefit that MAP seeks to foster.

Of the possible reasons for a Buddhist center to hesitate in offering a MAP series, a common one might be reluctance to engage in teachings that are not strictly Buddhist. Centers must discern for themselves their own best practices, though the continuing growth of interest in mindfulness as well as the connection between Buddhism and mindfulness suggest an opportune moment for Buddhist organizations in the West to be among the forefront of innovative mindfulness interventions. Furthermore, Buddhists might consider the second training precept, which guides practitioners not to take what is not freely offered. A positive interpretation of this tenet is to foster generosity in offering what is needed (Salzberg 1995; Goldstein and Kornfield 1987). While some Insight centers have laudable community service projects in place, most of them focus on providing material assistance. Along with these worthy offerings, Insight, and other Buddhist, centers might also do well to consider offering what is perhaps the greatest gift they can provide-that of mindfulness training. 
If a Buddhist center were to offer a MAP series, care would need to be taken not to proselytize to participants. While participants may choose to follow up a MAP series by attending a local Buddhist center, local resources for mindfulness or contemplative practice from other or no religious tradition should also be shared. The teacher for this pilot series did allude to his Buddhist training by way of introduction, and then proceeded to teach the series in a non-religious manner. Effort was made to speak of mindfulness practice instead of meditation, though many participants used the word meditation themselves. During several instances, participants spoke of God, Jesus, or the universe as an underlying reality or truth. One participant commented that the practice had touched her soul. While offering mindfulness in a secular tone could be most inviting for all, participants will bring their own religious sensibilities with them, which should be welcome in the room.

Racism was first mentioned in this series in a question raised by a participant in the third class-essentially, how can mindfulness help with racism? The teacher, who was white himself, had prepared a handout on this topic which he distributed and the group discussed. The teacher presented himself as an ally, and shared personally from antiracism and feminism training he had done and was currently engaged in. While naming the vulnerability of topics such as racism and sexism, the teacher encouraged a class environment where concerns could be shared freely without being taken personally by others in the room, and a rich conversation ensued in which several participants spoke of the challenge of racism in their lives.

While MAP may provide a safe, self-reflective environment in which to speak of racism for both people of color and whites, work is also needed to be done by whites within Insight Meditation centers. Sadly, it seems that POC groups are more common than white ally or white awareness groups, perpetuating the societal norm that diversity and inclusion efforts are the job of people of color (Buddhist Insight Network 2012). In light of the necessity and precedent of people of color gathering in solidarity within a structurally racist society, it is not surprising that POC groups outnumber white awareness groups in Insight centers. Though unsurprising, this dynamic is good cause for pause, and reflection on what it might be like to have anti-racism groups for whites established with the frequency of POC groups. What would it look like, and what would it take, for the white folks to do their own race work?

Amidst these dynamics there are signs of change. Members of the Insight Meditation Community of Washington (IMCW) have formed a group called White Awake in which participants meet monthly to examine the history of white privilege and its manifestation in their lives. Participants "support each other in actively dissolving systemic racism in our meditation communities and other venues", a process one participant said has "been beautiful...really, really sweet" work (Barker 2011). Also doing white awareness work is the Insight Meditation Center of Pioneer Valley (IMCPV), based in Easthampton, Massachusetts, which offered a day-long program in March, 2012, called Building Community Across Race. Tailored toward white participants, the workshop sought to "explore the ways we feel isolated and separate as white people, and to strengthen our ability to build authentic relationships across race" (IMCPV 2012). New York Insight is also a leader, offering both "Dukkha [suffering] of White Privilege" weekend trainings on site as well as an "Undoing Racism" workshop in partnership with and at the Insight Meditation Society in Bare, MA (NYI 2014). 
While the MAP model may have limitations, to the extent it has value to offer, it is perhaps developmentally premature in the evolution of race awareness within the Insight Meditation tradition, at least within most Insight centers. A sound next step might be to focus on spreading White Awake work within Insight groups as a preparatory step toward going out of the centers to connect across race, class, and other marginalizing factors in the community. Time, and ideally the collective wisdom (as opposed to the collective apathy), will tell.

A useful comparison may perhaps be drawn to the 2014 International Symposium for Contemplative Studies (ISCS) put on by the Mind \& Life Institute in conjunction with His Holiness the Dalai Lama. The pre-conference concentrated on contemplative and transformative education, and featured a keynote address by civil rights and structural racism expert John Powell. His remarks invited listeners to redress injustice, especially based on -isms such as racism and classism, within their work in contemplative pursuits. During the main conference that followed, however, just 5\% of the more than 300 featured talks and posters focused on race and class dynamics in the application of mindfulness and other contemplative technologies, a poster presentation of MAP being one of them (Mind \& Life 2014). As with Western Buddhism, a large number of ISCS attendees appeared to be white and well educated. Amidst Powell's, and others' talk of inclusion at the symposium, it remains to be seen what action will be taken.

A limitation of this pilot study was the small number of participants. While questionnaire results indicate benefits to these participants, caution should be taken not to generalize the results. More research is needed to further support the findings of this study. The use of validated measurements would strengthen follow up studies, as would the inclusion of a control group. Long term follow up is also needed to discover the extent to which MAP series attendees continue to practice mindfulness on their own or with other groups after the initial MAP series.

\section{Conclusion}

Amidst the above-mentioned limitations, this study suggests that the MAP model could present an effective structure for mindfulness training to be offered at community centers serving low-income neighborhoods. An important next step will be for the MAP model to be further piloted by more MAP teachers and in more locations, with a control group when possible. The use of validated scales should also be implemented, as well as long term follow up.

While more research is needed, MAP could offer a potentially unique and promising approach to increase mindfulness equity. With mindfulness-based practices continuing to gain popularity and to be shown as beneficial for a variety of clinical and nonclinical populations, MAP could provide one approach to sharing these benefits more broadly and with those who could benefit greatly. Western Buddhist centers could do well to consider broadening those benefitting from their teachings not only by making Western Buddhist centers more diverse, but by partnering with local service providers in offering secular mindfulness trainings to marginalized populations.

\section{Ethical Standards}

This pilot series was offered by the MAP teacher as an aspect of his graduate work at a major university. Upon review of the procedure and measures for this study by an 
appointed faculty reviewer, it was determined that formal IRB approval was not necessary for the pilot series and its questionnaire. Participants in the study attended classes by choice and were told orally and in writing that completing the questionnaires was optional and anonymous. Participants were told orally that responses to the questionnaires would be included in a graduate school thesis as well as possible future publications. Risk to participants was minimal in this class series.

\section{Endnote}

${ }^{a}$ Figure includes individuals who attended more than one retreat.

\section{Additional files}

Additional file 1: The MAP Model.

Additional file 2: Mindfulness Training Course Feedback.

Competing interests

The authors declare that they have no competing interests.

Received: 12 September 2014 Accepted: 17 November 2014

Published online: 31 December 2014

\section{References}

Alexander, Michelle. 2010. The New Jim Crow. New York: The New Press.

American Psychological Association. 2007. Report of the APA task force on socioeconomic status.

Analayo. 2003. Satipatthana: The direct path to realization. Cambridge: Windhorse Publications.

Barker, Kristin. 2011. Personal communication. 27 December 2011

Brown, Kirk Warren, and Richard M Ryan. 2003. The benefits of being present: Mindfulness and its role in psychological well-being. Journal of Personality and Social Psychology 84:822-848.

Buddhist Insight Network. 2012. http://www.buddhistinsightnetwork.org/sites/default/files/pdfs/Multiculturalism\%20in\% 20Insight\%20Meditation.pdf. Accessed 6 November 2014.

Cambridge Insight Meditation Center. 2010. 2010 diversity and inclusion survey. http://cimc.info/diversities.html. Accessed 24 April 2012.

Children's Defense Fund. 2007. America's cradle to prison pipeline.

City of Cambridge, MA Community Development Department. 2010. Neighborhood study and action plan, Fall.

Dutton, Mary, Diana Bermudez, Armely Matas, and Neely L Myers. 2011. Mindfulness-based stress reduction for low-income, predominantly African American women with PTSD and a history of intimate partner violence. Cognitive and Behavioral Practice. doi:10.1016/j.cbpra.2011.08.003.

Germer, CK. 2005. Mindfulness: What is it? What does is matter? In Mindfulness and Psychotherapy, ed. CK Germer, RD Siegel, and PR Fulton. New York: The Guilford Press.

Gilpin, Richard. 2008. The use of Theravada Buddhist practices and perspectives in mindfulness-based cognitive therapy, 227-251. Contemporary Buddhism, November.

Goldstein, Joseph, and Jack Kornfield. 1987. Seeking the heart of wisdom: The path of insight meditation. Boston: Shambhala Publications, Inc.

Hick, Steven F, and Charles Furlotte. 2010. An exploratory study of Radical Mindfulness Training with severely economically disadvantaged people: Findings of a Canadian study. Australian Social Work. September 2010: 281-298.

Insight Meditation Center of Pioneer Valley. 2012. http://insightpv.org/calendar/. Accessed 16 March 2012.

Insight Meditation Society. 2011a. Facts and Figures. http://dharma.org/about-us/faq. Accessed 3 October 2011.

Insight Meditation Society. 2011b. FAQ. http://dharma.org/about-us/faq. Accessed 7 October.

Insight Meditation Society. 2014. Commitment to diversity. http://www.dharma.org/about-us/diversity. Accessed 3 November 2014.

Jacob, Jeffrey, Emily Jovic, and Merlin B Brinkerhoff. 2009. Personal and planetary well-being: Mindfulness meditation, pro-environmental behavior and personal quality of life in a survey from the social justice and ecological sustainability movement. Social Indicators Research. 93(2):275-294.

Kabat-Zinn, Jon. 2003. Mindfulness-based interventions in context: past, present, and future. Clinical Psychology: Science and Practice 156:144-156.

Lui, Meizhu, Barbara Robles, Betsy Leondar-Wright, Rose Brewer, and Rebecca Adamson. 2006. The color of wealth: The story behind the U.S. racial wealth divide. New York: The New Press.

Mind \& Life Institute. 2014. International symposium for contemplative studies conference program.

Moskos, Peter. 2011. In Defense of Flogging. New York: Basic Books.

New York Insight. 2014. https://www.nyimc.org/sangha-diversity/. Accessed 6 November 2014.

Reiman, Jeffrey H. 2009. The rich get richer and the poor get prison. New Jersey: Prentice Hall.

Roth, Beth, and Lia Calle-Mesa. 2006. Mindfulness-based stress reduction (MBSR) with Spanish-speaking and Englishspeaking inner-city medical patients. In Mindfulness-Based Treatment Approaches: Clinician's Guide to Evidence Base and Applications, ed. Ruth Baer. Burlington: Academic. 
Roth, Beth, and Diane Robbins. 2004. Mindfulness-based stress reduction and health-related quality of life: Findings from a bilingual inner-city patient population. Psychosomatic Medicine 66:113-123.

Salzberg, Sharon. 1995. Loving-kindness: The revolutionary art of happiness. Boston: Shambhala Publications, Inc

Siegel, Ronald D. 2010. The mindfulness solution: Everyday practices for everyday problems. New York: The Guilford Press.

U.S. Census. 2010. Supplemental poverty measure. http://www.census.gov/prod/2011 pubs/p60-241.pdf. Accessed 20 December 2011

U.S. Census. 2011. Poverty of people, by sex: 1966-2010. http://www.census.gov/hhes/www/poverty/data/historical/ people.html. Accessed 20 December 2011.

World Hunger Education Service. 2011a. United States. http://www.worldhunger.org/us.htm. Accessed 27 December 2011.

World Hunger Education Service. 2011b. Hunger in America. United States hunger and poverty facts. http://www. worldhunger.org/us.htm. Accessed 3 October 2011.

Yang, Larry. 2012. Personal communication. 26 January 2012.

Submit your manuscript to a SpringerOpen ${ }^{\circ}$ journal and benefit from:

- Convenient online submission

- Rigorous peer review

- Immediate publication on acceptance

- Open access: articles freely available online

- High visibility within the field

- Retaining the copyright to your article 